\title{
Control of Postharvest Botrytis Fruit Rot of Strawberry by Volatile Organic Compounds of Candida intermedia
}

\author{
R. Huang, G. Q. Li, J. Zhang, L. Yang, H. J. Che, D. H. Jiang, and H. C. Huang
}

First, second, third, fourth, fifth, and sixth authors: State Key Laboratory of Agricultural Microbiology and Key Laboratory of Plant Pathology of Hubei Province, Huazhong Agricultural University, Wuhan 430070, China; and seventh author: Agriculture and Agri-Food Canada, Research Centre, Lethbridge, Alberta, T1J 4B1, Canada.

Current address of H. C. Huang: Plant Pathology Division, Taiwan Agricultural Research Institute, Wufeng, Taichung, Taiwan.

Accepted for publication 6 February 2011.

\begin{abstract}
Huang, R., Li, G. Q., Zhang, J., Yang, L., Che, H. J., Jiang, D. H., and Huang, H. C. 2011. Control of postharvest Botrytis fruit rot of strawberry by volatile organic compounds of Candida intermedia. Phytopathology 101:859-869.

A study was conducted to identify volatile organic compounds or volatiles produced by Candida intermedia strain C410 using gas chromatography-mass spectrometry, and to determine efficacy of the volatiles of $C$. intermedia in suppression of conidial germination and mycelial growth of Botrytis cinerea and control of Botrytis fruit rot of strawberry. Results showed that, among 49 volatiles (esters, alcohols, alkenes, alkanes, alkynes, organic acids, ketones, and aldehydes) identi-

the most abundant. Synthetic chemicals of 1,3,5,7-cyclooctatetraene; 3 methyl-1-butanol; 2-nonanone; pentanoic acid, 4-methyl-, ethyl ester; 3methyl-1-butanol, acetate; acetic acid, pentyl ester; and hexanoic acid, ethyl ester were highly inhibitory to conidial germination and mycelial growth of $B$. cinerea. Inhibition of conidial germination and mycelial growth of $B$. cinerea by volatiles of $C$. intermedia was also observed. Meanwhile, results showed that incidence and severity of Botrytis fruit rot of strawberry was significantly $(P<0.01)$ reduced by exposure of the strawberry fruit to the volatiles from $C$. intermedia cultures or $C$. intermedia-infested strawberry fruit. These results suggest that the volatiles of $C$. intermedia $\mathrm{C} 410$ are promising biofumigants for control of Botrytis fruit rot of strawberry.
\end{abstract} fied from $C$. intermedia cultures on yeast extract peptone dextrose agar, two compounds, 1,3,5,7-cyclooctatetraene and 3-methyl-1-butanol, were
Additional keywords: biological control.
Botrytis cinerea Pers. (teleomorph: Botryotinia fuckeliana (de Bary) Whetzel) is a cosmopolitan plant-pathogenic fungus, causing gray mold disease on $>200$ crop species, including strawberry (Fragaria $\times$ ananassa Duch.) (52). It causes leaf blight, blossom blight, and fruit rot of strawberry (55) and, among these Botrytis diseases, fruit rot is the most important and is usually responsible for severe pre- and postharvest losses for strawberry industry $(11,55)$.

Botrytis cinerea is a necrotrophic plant pathogen. It can secrete cell-wall-degrading enzymes such as polygalacturonases, pectin methylesterases, cellulases, and hemicellulases, and phytotoxic metabolites such as botrydial (7). These chemical factors facilitate infection of strawberry fruit by $B$. cinerea and development of soft rot symptoms. Thus far, there are no strawberry cultivars with high resistance to $B$. cinerea (11). Control of Botrytis fruit rot (BFR) of strawberry depends on application of fungicides at the pre- and postharvest stages (1,35). However, public concerns regarding contamination of strawberry fruit by fungicide residues and formation of fungicide-resistant strains of $B$. cinerea $(6,8,19,54,58)$ suggest a need to explore alternative measures for control of BFR of strawberry.

Fresh postharvest products usually arrive at supermarkets or shops directly, and in consumers' hands for consumption after storage for a certain period of time. Development of measures safe for human beings to control postharvest diseases is of foremost importance for food safety. Biological control using indigenous microorganisms is probably a safe approach for

Corresponding author: G. Q. Li; E-mail address: guoqingli@mail.hzau.edu.cn

doi:10.1094/PHYTO-09-10-0255

(c) 2011 The American Phytopathological Society reducing plant postharvest diseases caused by $B$. cinerea, including BFR of strawberry. Previous reports indicated that selected fungal species such as Aureobasidium pullulans (de Bary) G. Arnaud (29), Candida oleophila Montrocher (29), Clonostachys rosea (Link) Schroers, Samuels, Seifert \& W. Gams (=Gliocladium roseum Bainer) (45), Metschnikowia fructicola Kurtzman \& Droby (22), Pichia guilliermondii Wick. (53), Rhodotorula glutinis (Fresen.) F. C. Harrison (56), Trichoderma spp. (47), and Ulocladium atrum Preuss (2) are effective agents for suppression of BFR of strawberry under preharvest or postharvest conditions. The proposed mechanisms for control of BFR of strawberry by these biocontrol agents include antibiosis (45), mycoparasitism $(26,45)$, competition for nutrients and space (29), and suppression of sporulation of $B$. cinerea $(2,45)$.

Volatile organic compounds (VOCs) are substances of low molecular weight (usually $<300 \mathrm{Da}$ ), low polarity, and high vapor pressure (50). Production of VOCs with antimicrobial activity has been reported in bacteria $(5,15,17,21)$, Streptomyces spp. $(27,51)$, filamentous fungi $(23,43,44)$, yeasts $(3,16)$, and higher plants $(24,25)$. Antimicrobial VOCs from the plant-endophytic fungus Muscodor albus Worapng, Strobel \& W. M. Hess were found to have great potential for control of postharvest fruit diseases $(31,33,42)$ and soilborne plant diseases $(32,38)$. Previous reports also indicated that VOCs of Streptomyces platensis F-1 were effective for suppression of BFR of strawberry (51), and VOCs of 'Isabella' grape (Vitis labrusca L.) were effective for suppression of $B$. cinerea on table grape (V. vinifera L.) (24) and kiwi fruit (Actinidia deliciosa Liang and Ferguson) (25). Fialho et al. (16) reported that Saccharomyces cerevisiae Meyen ex E. C. Hansen can produce VOCs inhibitory to Guignardia citricarpa Kiely, the causal agent of citrus black spot (16). However, information on the potential of the VOCs produced by $S$. cerevisiae and other 
yeast species in biological control of plant diseases, including BFR of strawberry, is not available in literatures.

The yeast strain C410 of Candida intermedia (Cif. \& Ashford) Langeron \& Guerra was isolated from a healthy leaf of a strawberry plant grown in a greenhouse in Wuhan, China (18). Our previous study showed that application of strain C410 of $C$. intermedia to freshly harvested fruit of strawberry was effective in reducing incidence and severity of BFR of strawberry (18). This result suggests that strain $\mathrm{C} 410$ of $C$. intermedia is a potential agent for control of BFR of strawberry. Meanwhile, our preliminary observation indicates that cultures of strain C410 grown on yeast extract peptone dextrose agar (YEPDA) have a strong aromatic smell, suggesting release of VOCs. The objectives of this study were to (i) analyze the composition of the VOCs produced by strain $\mathrm{C} 410$ of $C$. intermedia and (ii) determine efficacy of the VOCs of $C$. intermedia in suppression of conidial germination and mycelial growth of $B$. cinerea and control of BFR of strawberry.

\section{MATERIALS AND METHODS}

Fungal strains and culture media. The yeast used in this study, strain C410 of $C$. intermedia, was identified on the basis of morphological and physiological characteristics, and the DNA sequence of the internal transcribed spacer (ITS) region (ITS15.8S rDNA-ITS2) of ribosomal gene (GenBank accession number GQ913345). Strain SB-1 of B. cinerea was isolated from a diseased fruit of strawberry collected from a greenhouse in Wuhan, China. Stock cultures of the two fungal strains were maintained on potato dextrose agar (PDA) and stored at $4^{\circ} \mathrm{C}$. Working cultures were prepared by transferring yeast cells of $C$. intermedia or mycelia of $B$. cinerea on PDA in petri dishes, and the cultures were incubated at $20^{\circ} \mathrm{C}$ for 3 to 5 days. Conidia of $B$. cinerea were harvested from 14-day-old PDA cultures (26). Yeast cells were harvested by washing the PDA cultures of $C$. intermedia with sterile distilled water. The resulting yeast cell suspensions $\left(\approx 1 \times 10^{9}\right.$ yeast cells $\left./ \mathrm{ml}\right)$ of $C$. intermedia and the conidial suspensions of $B$. cinerea $\left(1 \times 10^{7}\right.$ conidia $\left./ \mathrm{ml}\right)$ were used as inoculum for the bioassays of this study. The percentage of germinated conidia of $B$. cinerea was $>90 \%$.

Three culture media (PDA, water agar (WA), and YEPDA) were used in this study. PDA was made of fresh potato $(200 \mathrm{~g}$ of peeled potato, $20 \mathrm{~g}$ of glucose, $20 \mathrm{~g}$ of agar, and 1,000 ml water). WA contained $20 \mathrm{~g}$ of agar in $1,000 \mathrm{ml}$ of water. YEPDA contained $10 \mathrm{~g}$ of yeast extract, $20 \mathrm{~g}$ of peptone, $20 \mathrm{~g}$ of glucose, $20 \mathrm{~g}$ of agar, and $1,000 \mathrm{ml}$ of sterile distilled water. All these media were autoclaved at $121^{\circ} \mathrm{C}$ for $20 \mathrm{~min}$.

Gas chromatography-mass spectrometry analysis of the VOCs of $C$. intermedia. Yeast cells of strain C410 of $C$. intermedia were inoculated on YEPDA in petri dishes $(9 \mathrm{~cm}$ in diam- eter), $20 \mathrm{ml} / \mathrm{dish}$, at $\approx 1 \times 10^{8}$ yeast cells/dish. Fresh YEPDA without inoculation of $C$. intermedia (uncolonized) was used as control. The yeast cultures were incubated at $20^{\circ} \mathrm{C}$ for $24 \mathrm{~h}$ and the yeast biomass in each dish reached $10^{9}$ yeast cells. Then, a dish of the $C$. intermedia culture or uncolonized YEPDA was transferred to a $100-\mathrm{ml}$ extraction glass vial. The vial was sealed with a silicon rubber mat and incubated at $40^{\circ} \mathrm{C}$ for $15 \mathrm{~min}$ to equilibrate the solid phase and the phase of VOCs in the vial. A $50 / 30-\mu \mathrm{m}$ solid-phase microextraction fiber containing divinylbenzene/carboxen/polydimethylsiloxane (Supelco, Bellfonte, PA) was inserted into the vial for extraction of the VOCs from the yeast culture or the uncolonized YEPDA at $40^{\circ} \mathrm{C}$ for $40 \mathrm{~min}$. Then, the fiber was pulled out from the vial and inserted into the injection port of a gas chromatography-mass spectrometry (GCMS) (6890N-5975B; Agilent Technologies Inc., CA) equipped with a J \& WHP-5MS fused-silica capillary column (30 m by $0.25 \mathrm{~mm}$ i.d., $0.25-\mu \mathrm{m}$-thickness film) (Agilent Technologies Inc.) for separation of the VOCs. GC was operated in splitless mode with the injector temperature set at $250^{\circ} \mathrm{C}$. The column temperature was programmed as follows: $40^{\circ} \mathrm{C}$ for $3 \mathrm{~min}$, and then increased at $3^{\circ} \mathrm{C} / \mathrm{min}$ to $160^{\circ} \mathrm{C}$, held at $160^{\circ} \mathrm{C}$ for $2 \mathrm{~min}$, increased further at $8^{\circ} \mathrm{C} / \mathrm{min}$ to $220^{\circ} \mathrm{C}$, and finally held at $220^{\circ} \mathrm{C}$ for $3 \mathrm{~min}$. Helium (ultra-high purity) was used as the carrier gas, which was set at the flow rate of $1.2 \mathrm{ml} / \mathrm{min}$. MS was operated in electron ionization mode at $70 \mathrm{eV}$ and $230^{\circ} \mathrm{C}$. Mass spectra were obtained using a scan modus with the total ion counts within the range of 50 to $550 \mathrm{~m} / \mathrm{z}$. Identification of the VOCs was done by comparing the mass spectra and retention times of the individual VOC with those for the standard compounds deposited in the database of the National Institute of Standards and Technology (NIST)/EPA/NIH library (NIST05) and the Wiley Registry of Mass Spectral Database (Wiley 7.0) in the MS. Analysis of the VOCs in the sample of the $C$. intermedia culture or the uncolonized control was repeated twice. The VOC components appearing in both the culture of $C$. intermedia and the uncolonized YEPDA were not considered to be produced by $C$. intermedia.

Antifungal activity of the selected VOCs from $C$. intermedia (bioassay 1). Thirteen VOC components identified in YEPDA cultures of strain C410 of $C$. intermedia were selected (Table 1). These components were artificially synthesized by three chemical companies, including Sinopharm Chemical Reagent Co., Ltd. (Shanghai, China), Aladdin Reagent Database Inc. (Shanghai, China), and Sigma-Aldrich (St. Louis) (Table 1). The synthetic VOCs were individually tested for inhibition of mycelial growth of $B$. cinerea on PDA and for inhibition of conidial germination of $B$. cinerea on WA. The bioassay was done in closed petri dishes ( $9 \mathrm{~cm}$ in diameter) in the presence of $B$. cinerea and a given synthetic VOC. In the test for inhibition of mycelial growth, a mycelial agar plug removed from the colony margin of a 2-dayold PDA culture of $B$. cinerea was inoculated in a petri dish

TABLE 1. Synthetic volatile organic compounds used for testing antifungal activity against Botrytis cinerea in this study

\begin{tabular}{|c|c|c|c|}
\hline Compound & Source $^{\mathrm{a}}$ & Purity $(\%)(\text { grade })^{b}$ & Storage conditions \\
\hline Acetic acid, pentyl ester & A & $\geq 99.5(\mathrm{GC})$ & $4^{\circ} \mathrm{C}$, in darkness \\
\hline 1-Butanol, 3-methyl- & A & $\geq 98.5(\mathrm{AR})$ & $4^{\circ} \mathrm{C}$, in darkness \\
\hline 1-Butanol, 3-methyl-, acetate & A & $\geq 99.5$ (AR) & $4^{\circ} \mathrm{C}$, in darkness \\
\hline Butanoic acid, ethyl ester & $\mathrm{B}$ & $\geq 99.0(\mathrm{GC})$ & $4^{\circ} \mathrm{C}$, in darkness \\
\hline $1,3,5,7-$ Cyclooctatetraene & $\mathrm{C}$ & $98(\mathrm{GC})$ & $-20^{\circ} \mathrm{C}$, in darkness \\
\hline Ethyl acetate & A & $\geq 99.0$ (AR) & $4^{\circ} \mathrm{C}$, in darkness \\
\hline Hexanoic acid, ethyl ester & A & $\geq 99.5(\mathrm{GC})$ & $4^{\circ} \mathrm{C}$, in darkness \\
\hline 2-Nonanone & $\mathrm{B}$ & $>99.0$ (GC) & $4^{\circ} \mathrm{C}$, in darkness \\
\hline Pentanoic acid, 4-methyl-, ethyl ester & $\mathrm{C}$ & $\geq 97.0(\mathrm{GC})$ & $4^{\circ} \mathrm{C}$, in darkness \\
\hline Phenylethyl alcohol & $\mathrm{B}$ & $>99.5(\mathrm{GC})$ & $4^{\circ} \mathrm{C}$, in darkness \\
\hline Propanoic acid, ethyl ester & $\mathrm{B}$ & $\geq 99.7(\mathrm{GC})$ & $4^{\circ} \mathrm{C}$, in darkness \\
\hline Styrene & $\mathrm{B}$ & $>99.5$ (GC) & $4^{\circ} \mathrm{C}$, in darkness \\
\hline 1-Tetradecyne & $\mathrm{C}$ & $\geq 97.0(\mathrm{GC})$ & $4^{\circ} \mathrm{C}$, in darkness \\
\hline
\end{tabular}

a Sources: A, Sinopharm Chemical Reagent Co., Ltd, Shanghai, China; B, Aladdin Reagent Database Inc., Shanghai, China; C, Sigma-Aldrich, St. Louis.

b Grade: GC, gas chromatography; AR, analytical reagent. 
containing $20 \mathrm{ml}$ of PDA. Meanwhile, a piece of filter paper (1.6 by $1.5 \mathrm{~cm}$, length by width) was placed in the center of another petri dish $(9 \mathrm{~cm}$ in diameter). The synthetic VOCs tested were individually diluted to $0.1,0.5,1.0,2.5,5.0,10$, and $50 \%$ ( $\mathrm{vol} / \mathrm{vol}$ ) with anhydrous ethanol. An aliquot of $100 \mu \mathrm{l}$ of a diluted solution of a given VOC was pipetted onto the filter paper piece (FPP) in the dish. After cover removal, the PDA dish inoculated with a mycelial agar plug of $B$. cinerea was covered above the FPP dish containing an investigated VOC and the set of the double dishes (DD) was sealed using double layers of parafilm (Parafilm M, Chicago) to make a closed DD chamber of $\approx 180 \mathrm{~cm}^{3}$ in volume (Fig. 1A). For the control treatment, an aliquot of $100 \mu \mathrm{l}$ of anhydrous ethanol was pipetted on the FPP in a petri dish, which was covered above a PDA dish inoculated with a mycelial agar plug of $B$. cinerea. The DD set was also sealed using the parafilm. There were three DD sets (replicates) for the control treatment and for the given VOC treatment at each dilution point. The DD sets were incubated at $20^{\circ} \mathrm{C}$ for 3 days. Diameter of the colony of $B$. cinerea in each DD set was measured. The percentage of inhibition of mycelial growth of $B$. cinerea by a given VOC at each dilution point was calculated on the basis of the difference of the colony diameter between the

A
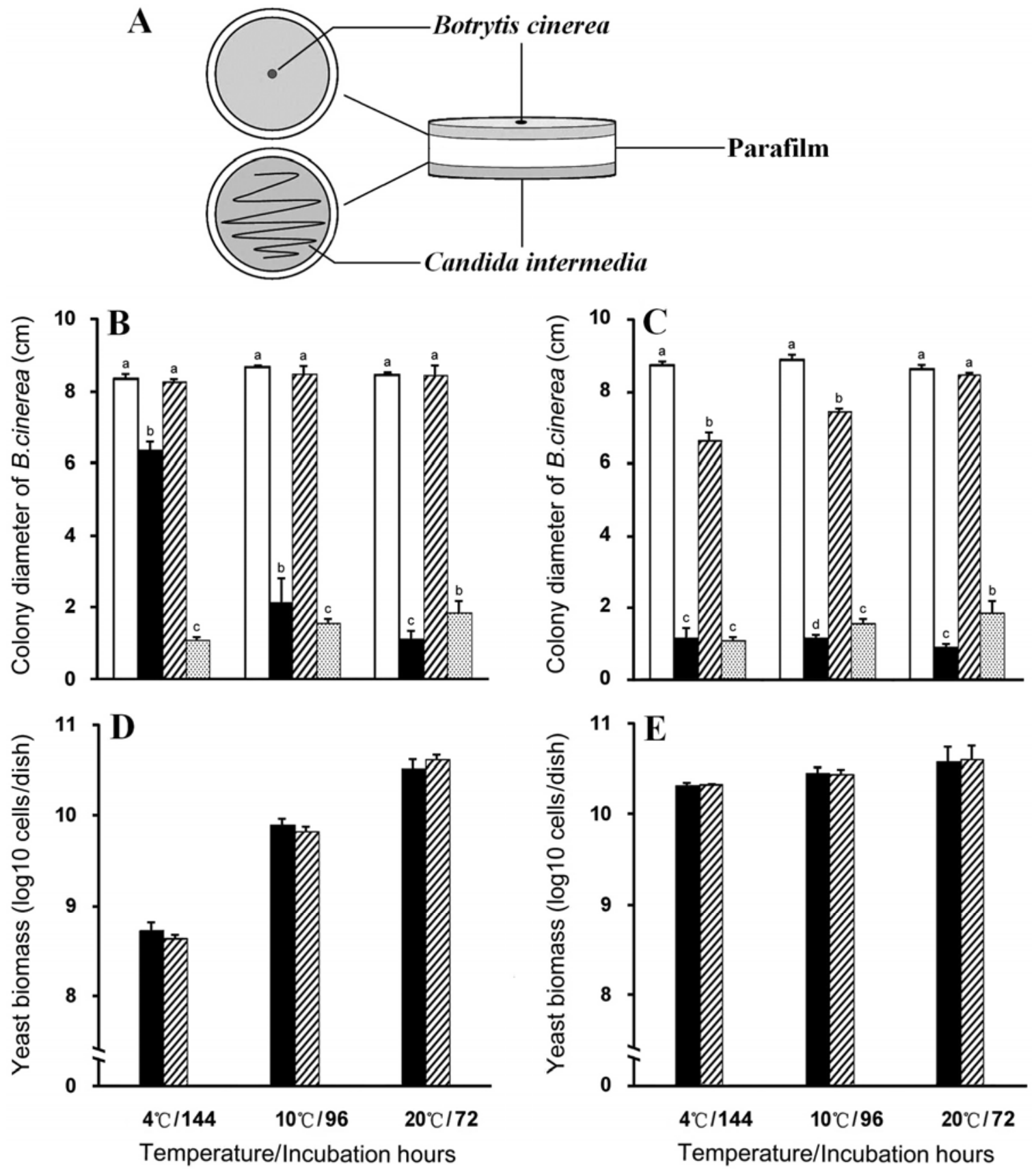

口Control aC410 $\mathrm{ZC4} 410+\mathrm{AC}$ 圆2-Nonanone

Fig. 1. Effects of the volatile organic compounds (VOCs) produced by Candida intermedia C410, the VOCs of $C$. intermedia plus activated carbon (AC) and 2nonanone on mycelial growth of Botrytis cinerea at different temperatures (bioassay 2). A, A schematic diagram showing the method for testing antifungal activity of the VOCs of $C$. intermedia, the VOCs of $C$. intermedia $+\mathrm{AC}$ and 2-nonanone; $\mathbf{B}$ and $\mathbf{C}$, Effects of the VOCs of $C$. intermedia, the VOCs of $C$. intermedia $+\mathrm{AC}$ and 2-nonanone on mycelial growth of $B$. cinerea in the simultaneous and nonsimultaneous co-incubation trials, respectively. $\mathbf{D}$ and $\mathbf{E}$, The yeast biomass of $C$. intermedia on yeast extract peptone dextrose agar in the simultaneous and nonsimultaneous co-incubation trials, respectively. Results in all the histograms are expressed as means \pm standard errors $(n=9)$. Mean values for different treatments at each temperature labeled with different letters indicate significant difference $(P<0.01)$ according to Fisher's protected least significant difference test. 
each control and tested VOC treatment. The concentration value for $50 \%$ inhibition of mycelial growth $\left(\mathrm{IC}_{50}\right)$ expressed as microliters per liter was inferred from the data about the inhibition percentages and the VOC doses applied to the DD sets (44).

For inhibition of conidial germination, aliquots of a conidial suspension $\left(1 \times 10^{7}\right.$ conidia/ml $)$ of $B$. cinerea were pipetted onto WA in petri dishes ( $9 \mathrm{~cm}$ in diameter), $100 \mu \mathrm{l} /$ dish. The conidial suspension in each dish was evenly spread on the surface of WA. After cover removal, a WA dish inoculated with conidia of $B$. cinerea was covered above a FPP dish containing anhydrous ethanol alone (control) or each ethanol-diluted VOC. The DD set was sealed using the parafilm. There were three DD sets for the each control and tested VOC treatment. The DD sets were incubated at $20^{\circ} \mathrm{C}$ for $12 \mathrm{~h}$. The frequency of conidial germination of $B$. cinerea was determined by randomly counting at least 150 conidia in each WA dish under a compound light microscope. A conidium was considered to have germinated when the length of the germ tube was equal to (or greater than) the diameter of that conidium. The percentage of inhibition of conidial germination of B. cinerea by a given VOC was calculated on the basis of the difference in the percentage of germinated conidia between the control and tested VOC treatments. The $\mathrm{IC}_{50}$ value for each investigated $\mathrm{VOC}$ was inferred from the data about the inhibition percentages of conidial germination and the VOC doses applied to the DD sets (44).

Suppression of mycelial growth of $B$. cinerea by the VOCs of $C$. intermedia (bioassay 2). Two trials, the simultaneous coincubation (SI) trial and the nonsimultaneous co-incubation (NSI) trial, were conducted in this bioassay. There were four treatments in each trial: (i) negative control, (ii) $C$. intermedia, (iii) $C$. intermedia + activated carbon (AC), and (iv) positive control (2nonanone). AC was used as the absorbent of the VOCs of $C$. intermedia in the $C$. intermedia $+\mathrm{AC}$ treatment $(15,50)$. In the SI trial, mycelial agar plugs ( $6 \mathrm{~mm}$ in diameter) of $B$. cinerea were inoculated in the center of petri dishes, each containing $20 \mathrm{ml}$ of PDA, one mycelial agar plug per dish. For the negative-control treatment, a PDA dish with $B$. cinerea was covered above a YEPDA dish containing uncolonized YEPDA to make a DD set. For the $C$. intermedia treatment, aliquots of the yeast cell suspension of $C$. intermedia $\left(1 \times 10^{9}\right.$ yeast cells $\left./ \mathrm{ml}\right)$ were pipetted to petri dishes each containing $20 \mathrm{ml}$ of YEPDA and $100 \mu \mathrm{l}$ of yeast cell suspension per dish. The suspension drop in each dish was evenly spread on the surface of YEPDA using a sterilized glass spatula. Then, a PDA dish with $B$. cinerea was covered above a YEPDA dish with $C$. intermedia to make a DD set (Fig. 1A). For the $C$. intermedia $+\mathrm{AC}$ treatment, a piece of cotton gauze (warp $\times$ weft $=21^{\mathrm{S}} \times 21^{\mathrm{S}}$; Nanchang Xiangyi Medical Apparatus Co., Ltd., Nanchang, Jiangxi Province, China) with an average opening size of $\approx 1 \mathrm{~mm}^{2}$ was covered above the YEPDA dish with C. intermedia. TT AC particles $(6 \mathrm{~g}, \approx 1 \mathrm{~cm}$ in diameter) (Guangzhou Huana Automobile Products Co., Ltd., Guang Dong, China) were placed on the gauze. Then, a PDA dish with $B$. cinerea was covered above the gauze and YEPDA dish to make a DD set. For the positive-control treatment, a PDA dish with $B$. cinerea was covered above a dish with an FPP soaked with $2.5 \mu$ l of undiluted 2-nonanone to make a DD set. All the DD sets were individually sealed with parafilm (Fig. 1A). For each treatment, there were nine DD sets which were divided into three groups, three DD sets per group. Finally, the three groups of DD sets were incubated at $4^{\circ} \mathrm{C}$ for 6 days, $10^{\circ} \mathrm{C}$ for 4 days, and $20^{\circ} \mathrm{C}$ for 3 days, respectively, for determination of the colony diameter of $B$. cinerea. Meanwhile, yeast cells of $C$. intermedia in each YEPDA dish for the $C$. intermedia and $C$. intermedia $+\mathrm{AC}$ treatments were washed off with sterile distilled water ( $10 \mathrm{ml}$ of water per dish) and the concentration of the resulting yeast cell suspensions was determined using a hemacytometer and a compound light microscope.

In the NSI trial, aliquots of the yeast cell suspension of $C$. intermedia $\mathrm{C} 410$ were pipetted and plated on YEPDA in petri dishes, $100 \mu \mathrm{l}$ of yeast cell suspension per dish, and the yeast cultures were incubated at $20^{\circ} \mathrm{C}$ for $24 \mathrm{~h}$. Mycelial agar plugs of $B$. cinerea were inoculated on PDA in petri dishes, one mycelial agar plug per dish. They were then individually covered above dishes containing uncolonized YEPDA, YEPDA cultures of $C$. intermedia (24 h old), YEPDA cultures of $C$. intermedia $(24 \mathrm{~h}$ old $)+\mathrm{AC}$, and 2-nonanone $(2.5 \mu \mathrm{l} / \mathrm{dish})$ for the treatments negative control, $C$. intermedia, $C$. intermedia $+\mathrm{AC}$, and positive control, respectively. The DD sets were individually sealed with parafilm (Fig. 1A). For each treatment, there were nine DD sets, which were divided into three groups, three DD sets per group. Finally, the three groups of DD sets were incubated at $4{ }^{\circ} \mathrm{C}$ for 6 days, $10^{\circ} \mathrm{C}$ for 4 days, and $20^{\circ} \mathrm{C}$ for 3 days, respectively, for determination of the colony diameter of $B$. cinerea. The bioassay was repeated three times.

Suppression of conidial germination of $B$. cinerea by the VOCs of $C$. intermedia (bioassay 3). Four treatments-negative control, $C$. intermedia, $C$. intermedia $+\mathrm{AC}$, and positive control (2-nonanone) - were included in both the SI trial and the NSI trial of this bioassay. The experiment procedures for this bioassay were similar to the procedures described for bioassay 2 of this study. In both trials, aliquots of the conidial suspension of $B$. cinerea $\left(1 \times 10^{7}\right.$ conidia/dish) were pipetted and plated on WA in petri dishes, $100 \mu \mathrm{l}$ per dish. They were individually covered above dishes containing uncolonized YEPDA, YEPDA cultures ( 0 or $24 \mathrm{~h}$ old) of $C$. intermedia, YEPDA cultures ( 0 or $24 \mathrm{~h}$ old) of $C$. intermedia $+\mathrm{AC}$, and 2-nonanone $(2.5 \mu \mathrm{l} / \mathrm{dish})$ for the negative control, $C$. intermedia, $C$. intermedia $+\mathrm{AC}$, and positive control treatments, respectively. The DD sets were individually sealed with parafilm (Fig. 1A) and incubated at $4^{\circ} \mathrm{C}$ for $48 \mathrm{~h}$, $10^{\circ} \mathrm{C}$ for $48 \mathrm{~h}$, or $20^{\circ} \mathrm{C}$ for $24 \mathrm{~h}$ for determination of germinated conidia and the length of germ tubes of $B$. cinerea on WA in each dish. Meanwhile, the yeast cells of $C$. intermedia in each YEPDA dish were washed with sterile distilled water for determination of the yeast biomass. The bioassay was repeated three times with three replicates for each treatment at each time.

Efficacy of the VOCs of $C$. intermedia in control of BFR of strawberry (bioassay 4). The bioassay was done in closed glass desiccators ( 18 by $23 \mathrm{~cm}$, diameter by height, $\approx 5.8$ liters in volume). Aliquots of the yeast cell suspension of $C$. intermedia $\left(1 \times 10^{9}\right.$ yeast cells $\left./ \mathrm{ml}\right)$ were pipetted and plated on YEPDA in petri dishes ( $9 \mathrm{~cm}$ in diameter) at $100 \mu \mathrm{l}$ of yeast cell suspension per dish. The dishes were incubated at $20^{\circ} \mathrm{C}$ for $24 \mathrm{~h}$ and the yeast biomass of $C$. intermedia reached $\approx 1 \times 10^{10}$ yeast cells per dish. The covers of the petri dishes were removed and the dishes with the cultures of $C$. intermedia were placed at the bottom of the desiccators at two, four, six, and eight dishes per desiccator. For the control treatment, two uncovered dishes with uncolonized YEPDA were placed in a desiccator. Mature and healthy strawberry fruit (Fragaria $\times$ ananassa 'Feng Xiang No. 5') were harvested from plants grown in a greenhouse in Wuhan, China. Fourteen unwounded strawberry fruit of similar size ( 3.0 to 3.5 by 2.0 to $2.5 \mathrm{~cm}$, length by width, 16 to $18 \mathrm{~g} /$ fruit) were surface sterilized in $70 \%$ ethanol for $3 \mathrm{~s}$, washed in sterile distilled water, blotted on paper towels, and individually inoculated with the conidial suspension $\left(\approx 1 \times 10^{7}\right.$ conidia/ml $)$ of $B$. cinerea on the surface of strawberry fruit, $100 \mu \mathrm{l}$ of conidial suspension per fruit. The fruit were then placed on the perforated ceramic clapboard above the uncovered dishes containing $C$. intermedia cultures or uncolonized YEPDA in a desiccator. There were four desiccators (replicates) for the control treatment or the $C$. intermedia treatments (two, four, six, and eight dishes of $C$. intermedia culture). The desiccators were individually covered and placed in an incubator at $20^{\circ} \mathrm{C}$ under a regime of $12 \mathrm{~h}$ of light and $12 \mathrm{~h}$ of darkness for 8 days. Strawberry fruit showing symptoms of soft rot and gray mold in each desiccator were individually rated for disease severity using a scale of 0 to 8 , where 0 represents healthy and $1,2,3,4,5,6,7$, and 8 represent $<12.5,12.6$ to $25.0,25.1$ to 
$37.5,37.6$ to $50.0,50.1$ to $62.5,62.6$ to $75.0,75.1$ to 87.5 , and 87.6 to $100 \%$ of the area rotted, respectively.

An additional experiment was conducted to verify the suppressive effect of the VOCs of $C$. intermedia on development of BFR of strawberry. There were three treatments in this experiment: (i) B. cinerea, (ii) B. cinerea $+C$. intermedia, and (iii) $B$. cinerea $+C$. intermedia $+\mathrm{AC}$. There were three desiccators (replicates) for each treatment. For the $B$. cinerea treatment, eight uncovered petri dishes with uninoculated YEPDA were placed at the bottom of each desiccator. For the B. cinerea $+C$. intermedia treatment, eight uncovered dishes with 24-h-old YEPDA cultures of $C$. intermedia $\left(20^{\circ} \mathrm{C}\right)$ were placed at the bottom of each desiccator. For the $B$. cinerea $+C$. intermedia $+\mathrm{AC}$ treatment, eight uncovered dishes with the YEPDA cultures of $C$. intermedia and $100 \mathrm{~g}$ of Hua Cao Si Ya AC powder (Hubei Huanggang Lv Yuan Jiajia Daily Necessities Manufacturer, Huang Gang, Hubei Province, China) were placed at the bottom of each desiccator. Healthy strawberry fruit were surface sterilized, individually inoculated with conidia of $B$. cinerea $\left(\approx 1 \times 10^{5}\right.$ conidia/fruit $)$, and placed on the clapboard of each desiccator, 14 fruit per desiccator. The desiccators were individually covered and incubated at $20^{\circ} \mathrm{C}$ for 8 days. Strawberry fruit in each desiccator were individually rated for incidence and severity of BFR using the rating scale described previously.

Control of BFR of strawberry by the VOCs from $C$. intermedia-infested fruit (bioassay 5). Three treatments-blank control, strawberry fruit (SF) with water (SF-water), and strawberry fruit with $C$. intermedia (SF-C. intermedia)-were included in this bioassay. There were three desiccators for each treatment representing three replicates. For the blank control treatment, the bottom space underneath the clapboard of each desiccator was left empty. For the SF-water treatment, 20 healthy strawberry fruit were dipped in sterile distilled water for $5 \mathrm{~s}$, blotted on paper towels, and loaded underneath the clapboard of a desiccator. For the SF- $C$. intermedia treatment, 20 healthy strawberry fruit were dipped in a yeast cell suspension of $C$. intermedia $\left(\approx 1 \times 10^{8}\right.$ yeast

TABLE 2. Volatile organic compounds (VOCs) released from Candida intermidia strain C410

\begin{tabular}{|c|c|c|c|}
\hline $\mathrm{RT}(\min )^{\mathrm{a}}$ & Possible compound ${ }^{\mathrm{b}}$ & $\mathrm{RA}(\%)^{\mathrm{c}}$ & $\mathrm{MW}(\mathrm{Da})^{\mathrm{c}}$ \\
\hline 0.80 & 1,6-Octadiene, 5,7-dimethyl-, (R)- & 0.100 & 138 \\
\hline 1.41 & 4,5-Nonadiene & 0.028 & 124 \\
\hline 1.50 & 1-Tetradecyne & 0.100 & 194 \\
\hline 2.13 & 5-Formyl-6-methyl-4,5-dihydropyran & 0.021 & 142 \\
\hline 3.54 & 1-Tridecyne & 0.014 & 180 \\
\hline 3.97 & 3-Octyne & 0.010 & 110 \\
\hline 4.86 & 1,19-Eicosadiene & 0.190 & 278 \\
\hline 6.31 & 1,2-15,16-Diepoxyhexadecane & 0.155 & 254 \\
\hline 6.70 & 19,19-Dimethyl-eicosa-8,11-dienoic acid & 0.207 & 336 \\
\hline 6.91 & 7-Oxabicyclo[4.1.0]heptane, 3-oxir & 0.045 & 140 \\
\hline 6.94 & 1,3,4-Hexatriene, 3-methoxy- & 0.003 & 110 \\
\hline 7.09 & Ethyl acetate & 1.086 & 88 \\
\hline 7.31 & Acetic acid, pentyl ester & 0.083 & 130 \\
\hline 8.12 & Z,Z-6,13-octadecadien-1-ol acetate & 0.045 & 308 \\
\hline 9.55 & Propanoic acid, ethyl ester & 0.431 & 102 \\
\hline 10.58 & 1-Butanol, 3-methyl- & 38.957 & 88 \\
\hline 13.11 & Butanoic acid, ethyl ester & 0.841 & 116 \\
\hline 14.21 & 2-Ethylacridine & 0.038 & 207 \\
\hline 16.80 & 1-Butanol, 3-methyl-, acetate & 1.738 & 130 \\
\hline 17.69 & 1,3,5,7-Cyclooctatetraene & 29.410 & 104 \\
\hline 18.39 & Styrene & 0.203 & 104 \\
\hline 20.66 & Benzeneacetonitrile, $\alpha$, -hydroxy- & 0.034 & 133 \\
\hline 20.92 & Benzeneethanamine, $\alpha, 2,6$-trimethyl- & 0.038 & 163 \\
\hline 21.41 & Pentanoic acid, 4-methyl-, ethyl ester & 1.962 & 144 \\
\hline 22.08 & 2,6-Dimethylbenzaldehyde & 0.038 & 134 \\
\hline 23.17 & Hexanoic acid, ethyl ester & 0.438 & 144 \\
\hline 23.45 & 2-Carbamoylphenoxyacetic acid & 0.024 & 195 \\
\hline 23.83 & 4-Ethylbenzoic acid, oct-3-en-2-yl ester & 0.024 & 246 \\
\hline 24.17 & Benzene, 1,3-dichloro- & 0.059 & 147 \\
\hline 24.24 & Benzene, 1,4-dichloro- & 0.028 & 147 \\
\hline 24.31 & Benzene, 1,2-dichloro- & 0.017 & 147 \\
\hline 24.69 & Spiro[3.5]nona-5,7-dien-1-one,5,9,9-trimethyl- & 0.010 & 176 \\
\hline 26.13 & Heptane, 4-methyl- & 0.121 & 114 \\
\hline 26.39 & 10,12-Octadecadiynoic acid & 0.076 & 276 \\
\hline 27.37 & Benzeneethanamine, $. \beta .-$ methyl- & 0.007 & 135 \\
\hline 27.64 & Pyrazine, 2,6-diethyl- & 0.345 & 136 \\
\hline 27.77 & 4-Pyridinamine, N,N,2-trimethyl- & 0.028 & 136 \\
\hline 28.10 & 2-Nonanone & 0.210 & 142 \\
\hline 29.34 & Cis,cis-7,10,-hexadecadienal & 0.007 & 236 \\
\hline 30.23 & Phenylethyl alcohol & 2.248 & 122 \\
\hline 32.32 & Preg-4-en-3-one, 17. $\alpha$-hydroxy- & 0.017 & 316 \\
\hline 32.62 & Cis-8-methyl-exo-tricyclo[5.2.1.0(2.6)] decane & 0.041 & 150 \\
\hline 32.85 & Cis-11-Hexadecenal & 0.021 & 238 \\
\hline 33.62 & 11,14-Eicosadienoic acid, methyl ester & 0.024 & 322 \\
\hline 33.98 & E,E-1,9,17-docasatriene & 0.010 & 304 \\
\hline 34.47 & 8-Dodecen-1-ol, acetate & 0.010 & 226 \\
\hline 34.60 & Cyclodecene & 0.010 & 166 \\
\hline 34.71 & Bicyclo[2.2.1]heptane, 2-methyl- & 0.028 & 110 \\
\hline 35.12 & 9-Octadecynoic acid, methyl ester & 0.028 & 294 \\
\hline
\end{tabular}

${ }^{\text {a }}$ Retention time in gas chromatography-mass spectrometry.

b VOCs of $C$. intermedia with the relative peak areas of $<0.001 \%$ are not included in this table.

c RA, relative peak area; MW, molecular weight. 
cells $/ \mathrm{ml}$ ) for $5 \mathrm{~s}$, blotted on paper towels, and loaded underneath the clapboard of each desiccator. Then, 14 healthy strawberry fruit were surface sterilized in $70 \%$ ethanol, rinsed in sterile distilled water, individually inoculated with aliquots of the conidial suspension of $B$. cinerea $\left(1 \times 10^{7}\right.$ conidia/ml $), 100 \mu \mathrm{l}$ per fruit, and placed on the clapboard of each desiccator for these three treatments. The desiccators were individually covered and incubated at $20^{\circ} \mathrm{C}$ for 8 days. Strawberry fruit on and beneath the clapboard in each desiccator were individually rated for incidence and severity of fruit rot using the rating scale described in bioassay 4.

Statistical analysis. All the statistical analyses in this study were conducted using SAS/STAT software (version 8.0; SAS Institute, Cary, NC). Data on colony diameter, percentage of germinated conidia (arcsine transformed), length of germ tubes, disease incidence (arcsine transformed), and disease severity in different repetitions were pooled for analysis. Means of each parameter for different treatments in each bioassay were compared using Fisher's protected least significant difference test $(P<0.01)$.

\section{RESULTS}

Identification of the VOCs from $C$. intermedia. Results of GC-MS analysis showed that 49 VOCs released from 1-day-old YEPDA cultures of $C$. intermedia $\mathrm{C} 410$ were identified on the basis of mass spectral properties (Table 2). These compounds fell into classes of esters, alcohols, alkenes, alkanes, alkynes, organic acids, ketones, aldehydes, benzenes, and amines. The most abundant compounds in the VOC profile of $C$. intermedia $\mathrm{C} 410$ were 1,3,5,7-cyclooctatetraene and 3-methyl-1-butanol. The relative peak area (RA) for these two VOCs accounted for 29.4 and $38.8 \%$, respectively. Eighteen VOCs were moderately abundant, with RA values of 0.1 to $2.2 \%$. They included acetic acid, pentyl ester; 1-butanol, 3-methyl-, acetate; butanoic acid, ethyl ester; 1,2-15,16-diepoxyhexadecane; 5,7-dimethyl-, (R)-; 19,19-dimethyl-eicosa-8, 11-dienoic acid; 1,19-eicosadiene; ethyl acetate; hexanoic acid, ethyl ester; heptane, 4-methyl-; 2-nonanone; 1,6octadiene; pentanoic acid, 4-methyl-, ethyl ester; phenylethyl alcohol; propanoic acid, ethyl ester; pyrazine, 2,6-diethyl-; styrene; and 1-tetradecyne. The other 29 VOCs were the least abundant, with RA values $<0.1 \%$.

Antifungal activity of the selected VOCs from $C$. intermedia (bioassay 1). Thirteen highly to moderately abundant VOCs

TABLE 3. Values of the $50 \%$ inhibition concentration $\left(\mathrm{IC}_{50}\right)$ of the synthetic volatile organic compounds for suppression of mycelial growth and conidial germination of Botrytis cinerea

\begin{tabular}{lcc}
\hline & \multicolumn{2}{c}{\begin{tabular}{c} 
IC $_{50}$ value $\left(\begin{array}{c}\text { mean } \pm \text { siter }) \\
\text { Compound }\end{array}\right.$ \\
\cline { 2 - 3 } Condard error $)$
\end{tabular}} \\
\cline { 2 - 3 } 2-Nonanone & $\begin{array}{c}\text { Mycelial } \\
\text { growth }^{\mathrm{a}}\end{array}$ & $\begin{array}{c}\text { Conidial } \\
\text { germination }^{\mathrm{b}}\end{array}$ \\
Pentanoic acid, 4-methyl-, ethyl ester & $6.5 \pm 0.5$ & $2.5 \pm 1.3$ \\
1,3,5,7-Cyclooctatetraene & $25.1 \pm 7.2$ & $11.9 \pm 1.9$ \\
1-Butanol, 3-methyl-, acetate & $16.5 \pm 1.3$ & $28.8 \pm 4.1$ \\
Acetic acid, pentyl ester & $21.0 \pm 2.4$ & $28.2 \pm 4.7$ \\
Hexanoic acid, ethyl ester & $46.5 \pm 3.6$ & $17.4 \pm 3.5$ \\
1-Butanol, 3-methyl- & $67.3 \pm 12.2$ & $18.6 \pm 3.7$ \\
Propanoic acid, ethyl ester & $70.2 \pm 1.6$ & $90.8 \pm 0.4$ \\
Butanoic acid, ethyl ester & $15.2 \pm 1.1$ & $>300.0$ \\
Phenylethyl alcohol & $18.6 \pm 6.4$ & $>280.0$ \\
Styrene & $29.9 \pm 5.0$ & $>500.0$ \\
Ethyl acetate & $>260.0$ & $42.1 \pm 3.6$ \\
1-Tetradecyne & $>280.0$ & $>580.0$ \\
\hline
\end{tabular}

${ }^{a}$ Mycelial growth of $B$. cinerea was determined on potato dextrose agar in petri dishes after the cultures were incubated at $20^{\circ} \mathrm{C}$ for $72 \mathrm{~h}$.

${ }^{\mathrm{b}}$ Conidial germination of $B$. cinerea was determined on water agar in petri dishes after the cultures were incubated at $20^{\circ} \mathrm{C}$ for $12 \mathrm{~h}$. produced by $C$. intermedia $\mathrm{C} 410$ were selected for testing their antifungal effects on $B$. cinerea. Artificially synthetic products of these VOCs were individually evaluated as fumigants in DD sets for inhibition of mycelial growth and conidial germination of $B$. cinerea. Results showed that 10 compounds (acetic acid, pentyl ester; butanoic acid, ethyl ester; 3-methyl-1-butanol; 1-butanol, 3methyl-, acetate; 1,3,5,7-cyclooctatetraene; hexanoic acid, ethyl ester; 2-nonanone; pentanoic acid, 4-methyl-, ethyl ester; phenylethyl alcohol; and propanoic acid, ethyl ester) effectively inhibited mycelial growth of $B$. cinerea, with $\mathrm{IC}_{50}$ values of 6.5 to $70.2 \mu \mathrm{l} /$ liter (Table 3). Of these 10 compounds, 7 (acetic acid, pentyl ester; 3-methyl-1-butanol; 1-butanol, 3-methyl-, acetate; 1,3,5,7-cyclo-octatetraene; hexanoic acid, ethyl ester; 2-nonanone; and pentanoic acid, 4-methyl-, ethyl ester) effectively inhibited conidial germination of $B$. cinerea, with $\mathrm{IC}_{50}$ values of 2.5 to $90.8 \mu \mathrm{l} /$ liter. Styrene could not inhibit mycelial growth of $B$. cinerea $\left(\mathrm{IC}_{50}>260 \mu \mathrm{l} /\right.$ liter $)$. However, it effectively inhibited conidial germination of this pathogen $\left(\mathrm{IC}_{50}=42.1 \mu \mathrm{l} /\right.$ liter $)$. Ethyl acetate and 1-tetradecyne could not inhibit mycelial growth and conidial germination of $B$. cinerea $\left(\mathrm{IC}_{50}>280 \mu \mathrm{l} /\right.$ liter $)$.

Suppression of mycelial growth of $B$. cinerea by the VOCs of $C$. intermedia (bioassay 2). After incubation at $4^{\circ} \mathrm{C}$ for 6 days, $10^{\circ} \mathrm{C}$ for 4 days, and $20^{\circ} \mathrm{C}$ for 3 days in both the SI and NSI trials, the average colony diameter of $B$. cinerea reached 11 to $18 \mathrm{~mm}$ in the positive control treatment (2-nonanone) and 83 to $89 \mathrm{~mm}$ in the negative control treatment (uncolonized YEPDA) (Fig. 1B and C). In the $C$. intermedia treatment ( $C$. intermedia on YEPDA), due to the presence of the VOCs from the cultures of $C$. intermedia (Fig. 1D and E), the average colony diameter of $B$. cinerea was 63,21 , and $11 \mathrm{~mm}$ at 4,10 , and $20^{\circ} \mathrm{C}$, respectively, in the SI trial (Fig. 1B), and 12, 12, and $9 \mathrm{~mm}$ at the same temperatures, respectively, in the NSI trial (Fig. 1C). A significant difference $(P<0.01)$ in the average colony diameter of $B$. cinerea was detected between the negative control and $C$. intermedia treatments at each temperature in each trial. However, the suppressive effect of the VOCs of $C$. intermedia on mycelial growth of $B$. cinerea was partially or completely nullified by AC in the $C$. intermedia $+\mathrm{AC}$ treatment. The average colony diameter of $B$. cinerea in this treatment reached 83 to $85 \mathrm{~mm}$ in the SI trial and 66 to $84 \mathrm{~mm}$ in the NSI trial. These colony-diameter values were significantly $(P<0.01)$ higher than those for the $C$. intermedia treatment but were not significantly $(P>0.01)$ different, or slightly different (although significantly different in terms of statistics), from those for the negative control treatment.

Suppression of conidial germination of $B$. cinerea by the VOCs of $C$. intermedia (bioassay 3). After incubation at $4^{\circ} \mathrm{C}$ for $48 \mathrm{~h}, 10^{\circ} \mathrm{C}$ for $48 \mathrm{~h}$, and $20^{\circ} \mathrm{C}$ for $24 \mathrm{~h}$, the percentage of germinated conidia of $B$. cinerea reached 1,86 , and $96 \%$, respectively, in the positive control treatment (2-nonanone) and $100 \%$ in the negative control treatment (uncolonized YEPDA) (Fig. 2). The average length of germ tubes of $B$. cinerea reached 19,52 , and $70 \mu \mathrm{m}$ at 4,10 , and $20^{\circ} \mathrm{C}$, respectively, in the positive control treatment and 289, 429, and $332 \mu \mathrm{m}$ at the same three temperatures, respectively, in the negative control treatment. In the $C$. intermedia treatment, the yeast biomass of $C$. intermedia in the SI trial $\left(0.3\right.$ to $9.6 \times 10^{9}$ yeast cells/dish) was lower than that in the NSI trial $\left(1.9\right.$ to $\left.3.0 \times 10^{10} \mathrm{cells} / \mathrm{dish}\right)$. As a result, the percentage of germinated conidia of $B$. cinerea in this treatment was $>90 \%$ ( 92 to $99 \%$ ) in the SI trial but $<30 \%(0.6$ to $29.0 \%$ ) in the NSI trial. The average length of germ tubes was 56 to $106 \mu \mathrm{m}$ in the SI trial and to $10 \mu \mathrm{m}$ in the NSI trial. However, in the $C$. intermedia + $\mathrm{AC}$ treatment, the suppressive effect of the VOCs of $C$. intermedia on conidial germination or extension of germ tubes of $B$. cinerea was partially or completely nullified by AC. The average percentage of germinated conidia of $B$. cinerea in this treatment reached 99 to $100 \%$ in the SI trial and 94 to $99 \%$ in the NSI trial. These percentage values were not significantly $(P<0.01)$ or slightly different from those in the negative control treatment. The average 
length of germ tubes of B. cinerea reached 212 to $299 \mu \mathrm{m}$ in the SI trial and 136 to $174 \mu \mathrm{m}$ in the NSI trial. These values were significantly $(P<0.01)$ higher than those in the $C$. intermedia treatment, although they were still significantly $(P<0.01)$ lower than those in the negative control treatment.

Efficacy of the VOCs of $C$. intermedia in control of BFR of strawberry (bioassay 4). After incubation at $20^{\circ} \mathrm{C}$ for 8 days, all the strawberry fruit in the control treatment (uncolonized YEPDA) showed soft rot and gray mold symptoms, with the BFR severity reaching 7.8 (Fig. 3). However, in the presence of the cultures of $C$. intermedia $\mathrm{C} 410$ increasing from $2 \times 10^{10}$ to $8 \times 10^{10}$ yeast cells/desiccator (5.8 liters in volume), the average BFR incidence of strawberry decreased from 93 to $18 \%$ and the average BFR severity value decreased from 3.9 to 0.3 .

Results of the additional experiment showed that the VOCs of $C$. intermedia in the $C$. intermedia treatment were highly effective in suppression of BFR of strawberry (Fig. 4). However, the suppressive effect of the VOCs of $C$. intermedia on BFR of strawberry in the $C$. intermedia $+\mathrm{AC}$ treatment was greatly nullified by AC (Fig. 4). The average BFR incidence reached $100 \%$ and the average BFR severity value reached 7.3 in this treatment. These values were significantly $(P<0.01)$ higher than those in the $C$. intermedia treatment but not significantly different $(P>0.01)$ from those in the control treatment (Fig. 4).

Control of BFR of strawberry by the VOCs from $C$. intermedia-infested fruit (bioassay 5). In the blank control and SF-water treatments, all the $B$. cinerea-inoculated strawberry fruit on the clapboards of the closed desiccators showed soft rot and gray mold symptoms (Fig. 5A). The BFR severity of strawberry reached 7.6 and 7.9 for these two treatments, respectively (Fig. $5 \mathrm{~B})$. Moreover, in the SF-water treatment, all the water-treated fruit of strawberry underneath the clapboard of the desiccators showed symptoms of soft rot and the average fruit rot severity
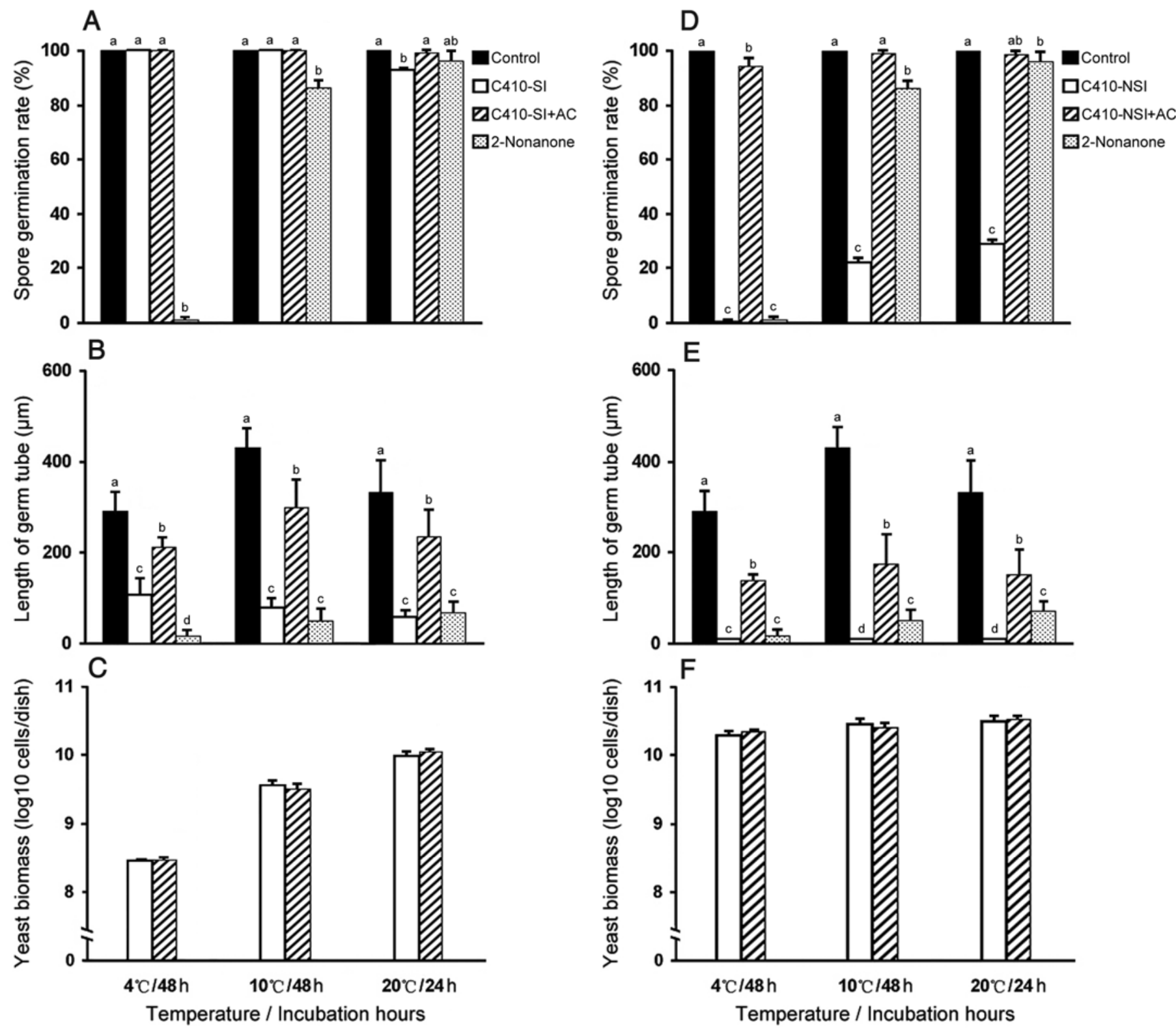

Fig. 2. Effects of the volatile organic compounds (VOCs) produced by Candida intermedia C410, the VOCs of $C$. intermedia plus activated carbon (AC) and 2nonanone on conidial germination and germ-tube extension of Botrytis cinerea on water agar (WA) under different temperatures (bioassay 3 ). A, B, and C, The percentage of germinated conidia (A) and the length of germ tubes of $B$. cinerea on WA (B), and the yeast biomass of $C$. intermedia on yeast extract peptone dextrose agar (YEPDA) (C) in the simultaneous co-incubation (SI) trial. D, E, and F, The percentage of germinated conidia (D), the length of germ tubes of $B$. cinerea on WA $(\mathbf{E})$, and the yeast biomass of $C$. intermedia on YEPDA $(\mathbf{F})$ in the nonsimultaneous co-incubation (NSI) trial. Results in all the histograms are expressed as means \pm standard errors $(n=9)$. Mean values for different treatments at each temperature labeled with different letters indicate significant difference $(P<0.01)$ according to Fisher's protected least significant difference test. 
reached 7.6 (Fig. 5B). In contrast, in the SF-C. intermedia treatment, most of the B. cinerea-inoculated fruit of strawberry on the clapboards of the desiccators appeared healthy (Fig. 5A). The average BFR incidence was $14 \%$ and the average BRF severity value was 0.1 (Fig. 5B). Moreover, in this treatment, growth and proliferation of $C$. intermedia on the surface of $C$. intermediatreated strawberry fruit underneath the clapboard of the desiccators were visible, showing slimy and milky symptoms (Fig. $5 \mathrm{~A}$ ). The average fruit rot incidence was $29 \%$ and the average fruit rot severity value was 0.6 .

\section{DISCUSSION}

Numerous studies indicate that selected strains of many plant epiphytic yeast species, including $C$. ciferrii (49), C. oleophila $(29,34)$, C. saitoana Nakase \& M. Suzuki (14), and C. sake (Saito \& M. Ota) Uden \& H. R. Buckley ex S. A. Mey. \& Ahearn (37), are effective agents for control of postharvest fruit diseases caused by fungal pathogens including $B$. cinerea. Liang and Chi (28) reported that strain $\mathrm{C} 3$ of $C$. intermedia isolated from decayed seed of corn was effective in controlling onion bulb rot caused by Aspergillus niger Tiegh. and fruit rot of citrus, orange, and apple caused by Penicillium spp. (28). Our study confirms the report of Huang et al. (18), who reported that strain C410 of $C$. intermedia isolated from a healthy strawberry leaf was effective in suppression of BFR of strawberry when yeast cells of this strain were inoculated on strawberry fruit (18). Numerous studies suggest that the mechanisms involved in biocontrol of $B$. cinerea and other plant fungal pathogens by yeasts include nutrient competition and site exclusion $(10,28,29,37,41,57)$, restriction of conidial germination and hyphal growth of fungal pathogens $(4,13)$, production of $1,3-\beta$-exoglucanase $(20,30)$, and induction of plant defense responses $(12,14,46,57)$. Our study reveals that the VOCs produced by $C$. intermedia $\mathrm{C} 410$ grown on YEPDA and strawberry fruit can effectively suppress the development of BFR of strawberry through suppression of conidial germination and mycelial growth of $B$. cinerea. These results suggest that pro-

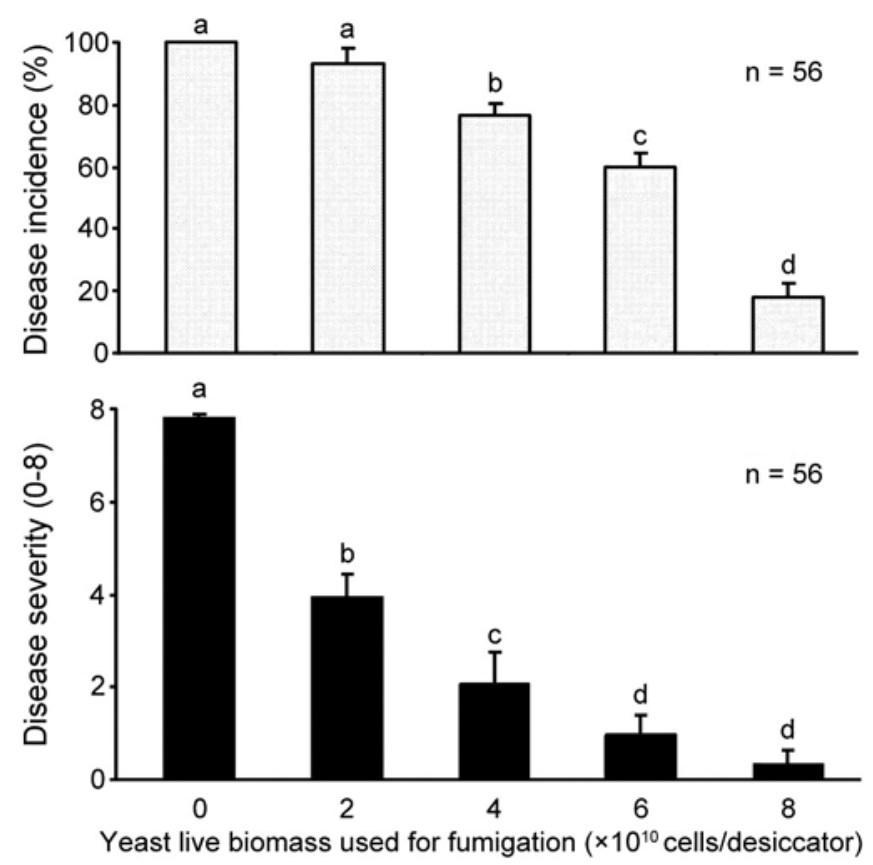

Fig. 3. Effect of the volatile organic compounds from Candida intermedia $\mathrm{C} 410$ on suppression of botrytis fruit rot of strawberry $\left(20^{\circ} \mathrm{C}, 8\right.$ days $)$ (bioassay 4). Results in the two histograms are expressed as means \pm standard errors. Mean values for different treatments with the same letters in each histogram are not significantly different $(P>0.01)$ according to Fisher's protected least significant difference test. duction of antifungal VOCs by yeasts might be an important mechanism for suppression of infection of plant tissues by $B$. cinerea under airtight conditions.

The present study reveals that 1,3,5,7-cyclooctatetraene, 3methyl-1-butanol, 2-nonanone, and phenylethyl alcohol are the VOCs produced by $C$. intermedia. Strobel et al. (44) and Mitchell et al. (36) reported that the plant-endophytic fungi $M$. albus (44) and $M$. crispans (36) can produce a mixture of VOCs, including 3-methyl-1-butanol, 2-nonanone, and phenylethyl alcohol. The compound 2-nonanone was also found in the VOC mixture released from cultures of Bacillus subtilis (5) and even from mature fruit of strawberry (48). Stinson et al. (43) indicated that another plant-endophytic fungus (Gliocladium sp.) can produce 1,3,5,7cyclooctatetraene (43). These findings suggest that some of the VOCs of $C$. intermedia are also produced by other organisms.

Previous studies indicate that antimicrobial VOCs produced by fungi or bacteria are effective biofumigants for control of plant diseases under airtight conditions. For example, the VOCs produced by strains of $M$. albus effectively controlled fruit decay caused by Botrytis cinerea in closed chambers $(31,33,42)$, or soilborne plant pathogens such as Rhizoctonia solani Kühn, Phytophthora capsici Leonian (32), and nematodes (38) in soil. Koitabashi (23) reported that Irpex lacteus (Fr.) Fr., a wooddecaying basidiomycete, produces two antifungal volatiles, 5pentyl-2-furaldehyde and 5-(4-pentenyl)-2-furaldehyde (23). Application of the cultures of I. lacteus in greenhouse effectively suppressed parsley powdery mildew caused by Oidium spp. (23). Our present study demonstrates that the VOCs released from cultures of $C$. intermedia or $C$. intermedia-infested fruit of straw-
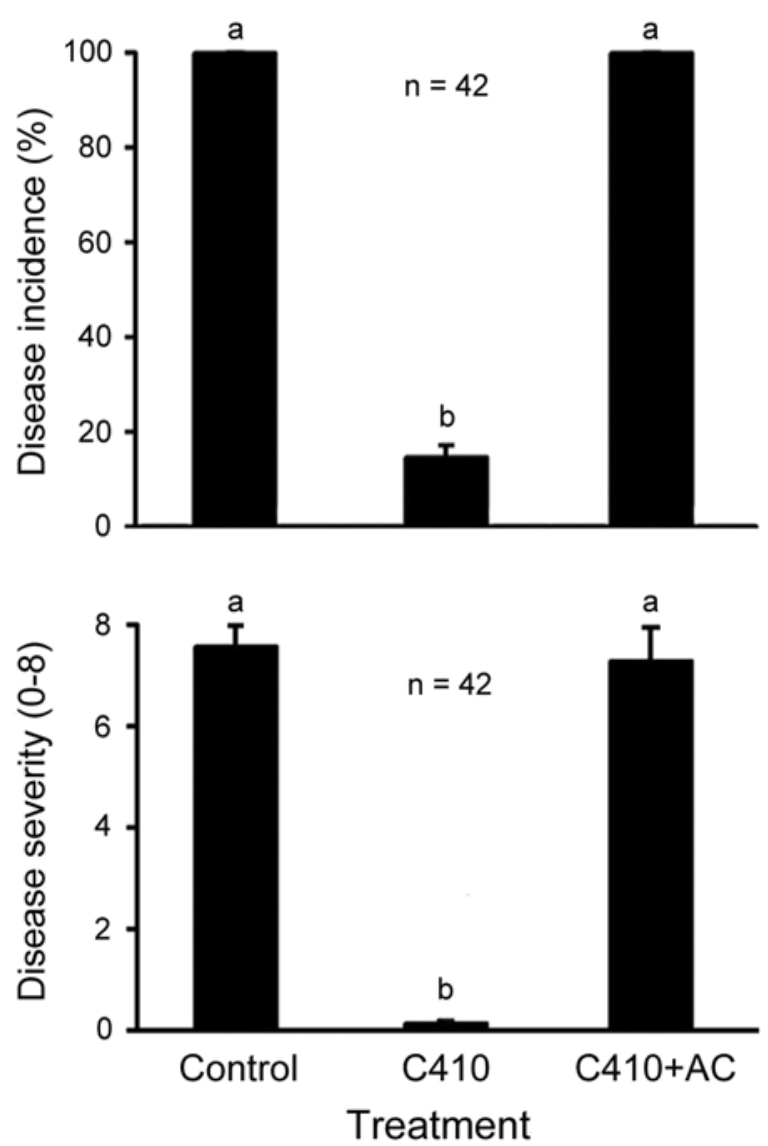

Fig. 4. Effect of the volatile organic compounds (VOCs) from Candida intermedia strain $\mathrm{C} 410$ and the VOCs of $C$. intermedia plus activated carbon (AC) on suppression of botrytis fruit rot of strawberry $\left(20^{\circ} \mathrm{C}, 8\right.$ days) (bioassay 4 ). Results in the two histograms are expressed as means \pm standard errors. Mean values for different treatments with the same letters in each histogram are not significantly different $(P>0.01)$ according to Fisher's protected least significant difference test. 

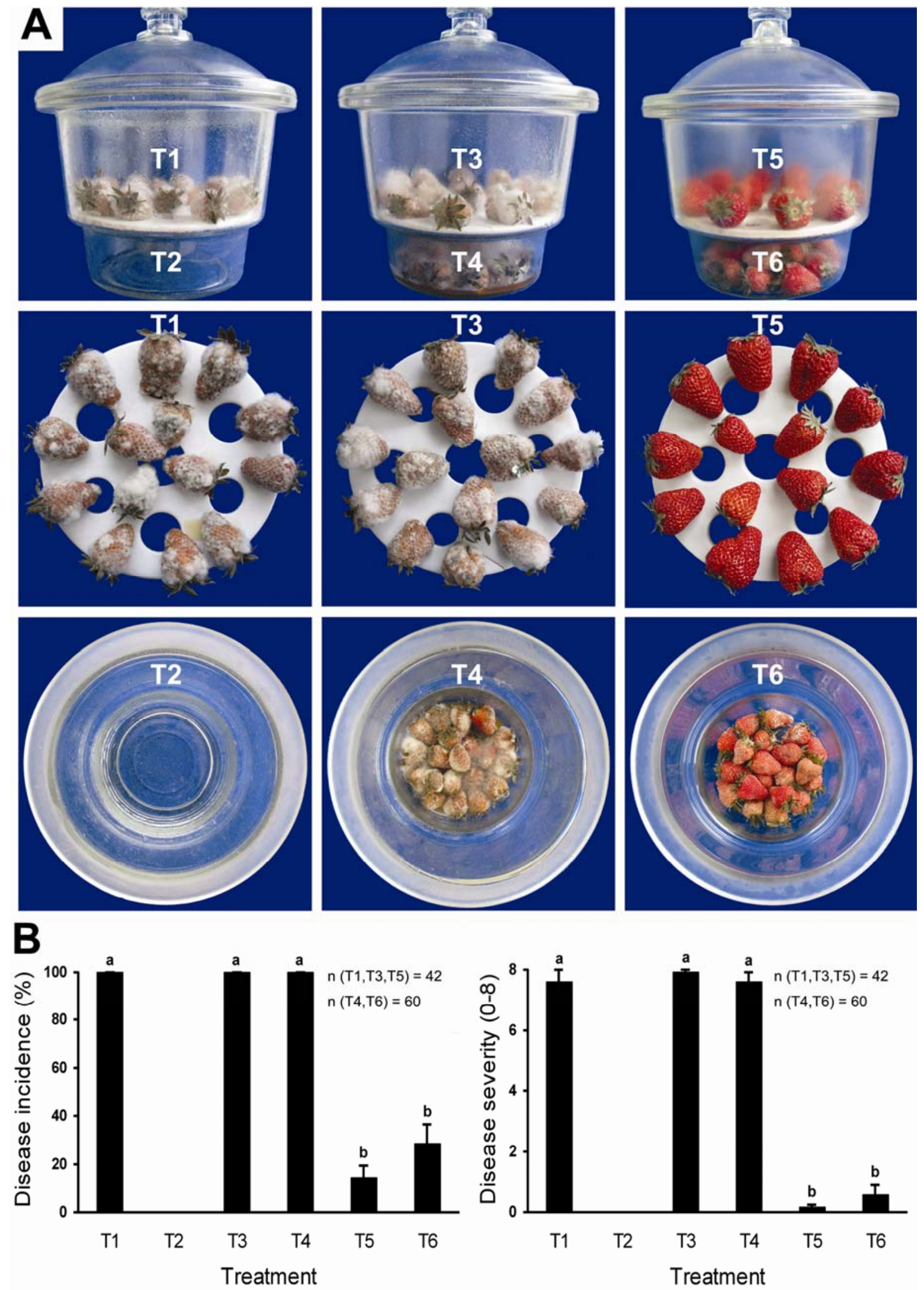

Fig. 5. Effect of the volatile organic compounds from Candida intermedia-infested fruits of strawberry on suppression of botrytis fruit rot of strawberry (20 ${ }^{\circ} \mathrm{C}, 8$ days) (bioassay 5). A, Set-up of the experiment showing different treatments (T1/T2, T3/T4, and T5/T6) in three desiccators (the top row) and strawberry fruits with or without gray mold symptoms (the bottom two rows). The results are one of the three repetitions in this bioassay. T1, T3, and T5, strawberry fruits inoculated with conidia of Botrytis cinerea and placed on the clapboard of each desiccator; T2, blank control (empty) beneath the clapboard of the desiccator; T4, strawberry fruits treated with water and placed beneath the clapboard of the desiccator; and T6, strawberry fruits inoculated with $C$. intermedia and placed beneath the clapboard of the desiccator. Note the colonization of $C$. intermedia on the surface of strawberry fruits resulting in formation of slimy and milky appearance. B, Two histograms showing incidence and severity of botrytis fruit rot of strawberry. Results in the two histograms are expressed as means \pm standard errors. Mean values for different treatments with the same letters in each histogram are not significantly different $(P>0.01)$ according to Fisher's protected least significant difference test. 
berry are effective in reducing incidence and severity of BFR of strawberry. Therefore, strain C410 of $C$. intermedia can be potentially developed as a biofumigant for control of this important pre- and postharvest disease of strawberry fruit. Further tests for evaluation of the efficacy of application of $C$. intermedia C410 on a large scale for control of BFR of strawberry are warranted.

C. intermedia has been recorded as an opportunistic pathogen that causes, or may be related to, infection of human beings, although cases of human infection by this yeast species are rare $(9,39,40)$. Strain C410 of $C$. intermedia investigated in this study was isolated from a healthy strawberry leaf (18). Whether or not this particular strain of $C$. intermedia is pathogenic or toxic to human beings remains unknown. Further studies to clarify the potential risk of strain $\mathrm{C} 410$ of $C$. intermedia as a biocontrol agent used for control of BFR of strawberry as well as Botrytis diseases on other economic crops are warranted.

\section{ACKNOWLEDGMENTS}

This research was funded by the Natural Science Foundation of China (Grant No. 31070122). We thank G. Fan, College of Food Science and Technology, Huazhong Agricultural University, Wuhan, China, for help in the analysis of volatile organic compounds produced by Candida intermedia.

\section{LITERATURE CITED}

1. Blacharski, R. W., Bartz, J. A., Xiao, C. L., and Legard, D. E. 2001. Control of postharvest Botrytis fruit rot with pre-harvest fungicide applications in annual strawberry. Plant Dis. 85:597-602.

2. Boff, P., Köhl, J., Jansen, M., Horsten, P. J. F. M., Lombaers-van der Plas, C., and Gerlagh, M. 2002. Biological control of gray mold with Ulocladium atrum in annual strawberry crops. Plant Dis. 86:220-224.

3. Bruce, A., Verrall, S., Hackett, C. A., and Wheatley, R. E. 2004. Identification of volatile organic compounds (VOCs) from bacteria and yeast causing growth inhibition of sapstain fungi. Holzforschung 58:193198.

4. Buck, J. W. 2002. In vitro antagonism of Botrytis cinerea by phylloplane yeasts. Can. J. Bot. 80:885-891.

5. Chen, H., Xiao, X., Wang, J., Wu, L. J, Zheng, Z. M., and Yu, Z. L. 2008. Antagonistic effects of volatiles generated by Bacillus subtilis on spore germination and hyphal growth of the plant pathogen, Botrytis cinerea. Biotechnol. Lett. 30:919-923.

6. Chen, L., Chen, Q., Ding, K. J., and Tan, G. J. 2007. Study on the resistance of Botrytis cinerea from strawberry to procymidine. Chinese Agric. Sci. Bull. 23:334-337. (In Chinese)

7. Choquer, M., Fournier, E., Kunz, C., Levis, C., Pradier, J. M., Simon, A., and Viaud, M. 2007. Botrytis cinerea virulence factors: New insights into a necrotrophic and polyphageous pathogen. FEMS Microbiol. Lett. 277:1-10.

8. Diánez, F., Santos, M., Blanco, R., and Tello, J. C. 2002. Fungicide resistance in Botrytis cinerea isolates from strawberry crops in Huelva (Southwestern Spain). Phytoparasitica 30:529-534.

9. Dokko, E., Kmetova, M., Pilipcinec, E., Bracokova, I., Dokko, F., Danko, J., Svichy, E., and Tkcikova, L. 2000. Rare non-albicans Candida species detected in different clinical diagnoses. Folia Microbiol. 45:364-368.

10. Droby, S., Chalutz, E., Wilson, C. L., and Wisniewski, M. E. 1989. Characterization of the biocontrol activity of Debaryomyces hansenii in the control of Penicillium digitatum on grapefruit. Can. J. Microbiol. 35:794-800.

11. Droby, S., and Lichter, A. 2004. Post-harvest Botrytis infection: Etiology, development and management. Pages 349-367 in: Botrytis: Biology, Pathology and Control. Y. Elad, B. Williamson, P. Tudzynski, and N. Delen, eds. Kluwer Academic Publishers, Dordrecht, The Netherlands.

12. Droby, S., Vinokur, V., Weiss, B., Cohen, L., Daus, A., Goldschmidt, E. E., and Porat, R. 2002. Induction of resistance to Penicillium digitatum in grapefruit by the yeast biocontrol agent Candida oleophila. Phytopathology 92:393-399.

13. El-Ghaouth, A., Wilson, C. L., and Wisniewski, M. 1998. Ultrastructural and cytochemical aspects of the biological control of Botrytis cinerea by Candida saitoana in apple fruit. Phytopathology 88:282-291.

14. El-Ghaouth, A., Wilson, C. L., and Wisniewski, M. 2003. Control of postharvest decay of apple fruit with Candida saitoana and induction of defense responses. Phytopathology 93:344-348.
15. Fernando, W. G. D., Ramarathnam, R., Krishnamoorthy, A. S., and Savchuk, S. C. 2005. Identification and use of potential bacterial organic antifungal volatiles in biocontrol. Soil Biol. Biochem. 37:955-964.

16. Fialho, M. B., Toffano, L., Pedroso, M. P., Augusto, F., and Pascholati, S. F. 2010. Volatile organic compounds produced by Saccharomyces cerevisiae inhibit the in vitro development of Guignardia citricarpa, the causal agent of citrus black spot. World J. Microbiol. Biotechnol. 26:925-932.

17. Gu, Y. Q., Mo, M. H., Zhou, J. P., Zou, C. S., and Zhang, K. Q. 2007. Evaluation and identification of potential organic nematicidal volatiles from soil bacteria. Soil Biol. Biochem. 39:2567-2575.

18. Huang, R., Li, G. Q., Yang, L., and Jiang, D. H. 2010. Efficacy and mechanisms of strain $\mathrm{C} 410$ of Candida intermedia in postharvest biocontrol of Botrytis fruit rot of strawberry. Page 654 in: Proc. Annu. Meet. Chinese Soc. Plant Pathol. Y. L. Peng and Z. H. Wang, eds. Beijing: Chinese Agricultural Science and Technology Press.

19. Hunter, T., Brent, K. J., Carter, G. A., and Hutcheon, J. A. 1987. Effects of fungicide spray regimes on incidence of dicarboximide resistance in gray mould (Botrytis cinerea) on strawberry plants. Ann. Appl. Biol. 110:515-525.

20. Jijakli, M. H., and Lepoivre, P. 1998. Characterization of an exo- $\beta-1,3-$ glucanase produced by Pichia anomala strain K, antagonist of Botrytis cinerea on apples. Phytopathology 88:335-343.

21. Kai, M., Effmert, U., Berg, G., and Piechulla, B. 2007. Volatiles of bacterial antagonists inhibit mycelial growth of the plant pathogen Rhizoctonia solani. Arch. Microbiol. 187:351-360.

22. Karabulut, O. A., Tezcan, H., Daus, A., Cohen, L., Wiess, B., and Droby, S. 2004. Control of preharvest and postharvest fruit rot in strawberry by Metschnikowia fructicola. Biocontrol Sci. Technol. 14:513-521.

23. Koitabashi, M. 2005. New biocontrol method for parsley powdery mildew by the antifungal volatiles-producing fungus Kyu-W63. J. Gen. Plant Pathol. 71:280-284.

24. Kulakiotu, E. K., Thanassoulopoulos, C. C., and Sfakiotakis, E. M. 2004. Biological control of Botrytis cinerea by volatiles of 'Isabella' grapes. Phytopathology 94:924-931.

25. Kulakiotu, E. K., Thanassoulopoulos, C. C., and Sfakiotakis, E. M. 2004. Postharvest biological control of Botrytis cinerea on kiwifruit by volatiles of 'Isabella' grapes. Phytopathology 94:1280-1285.

26. Li, G. Q., Huang, H. C., Kokko, E. G., and Acharya, S. N. 2002. Ultrastructural study of mycoparasitism of Gliocladium roseum on Botrytis cinerea. Bot. Bull. Acad. Sin. 43:211-218.

27. Li, Q. L., Ning, P., Zheng, L., Huang, J. B., Li, G. Q., and Hsiang, T. 2010. Fumigant activity of volatiles of Streptomyces globisporus JK-1 against Penicillium italicum on Citrus microcarpa. Postharvest Biol. Technol. 58:157-165.

28. Liang, Q. F., and Chi, Z. M. 2002. Study on antagonistic effect and mechanism by Candida intermedia for biological control of moulds on vegetables and fruits. Food Ferment. Ind. 28:34-38. (In Chinese)

29. Lima, G., Ippolito, A., Nigro, F., and Salerno, M. 1997. Effectiveness of Aureobasidium pullulans and Candida oleophila against postharvest strawberry rots. Postharvest Biol. Technol. 10:169-178.

30. Masih, E. I., and Paul, B. 2002. Secretion of $\beta-1,3$-glucanases by the yeast Pichia membranifaciens and its possible role in the biocontrol of Botrytis cinerea causing gray mould disease of the grapevine. Curr. Microbiol. 44:291-395.

31. Mercier, J., and Jiménez, J. I. 2004. Control of fungal decay of apples and peaches by the biofumigant fungus Muscodor albus. Postharvest Biol. Technol. 31:1-8.

32. Mercier, J., and Manker, D. C. 2005. Biocontrol of soil-borne diseases and plant growth enhancement in greenhouse soilless mix by the volatileproducing fungus Muscodor albus. Crop Prot. 24:355-362.

33. Mercier, J., and Smilanick, J. L. 2005. Control of green mold and sour rot of stored lemon by biofumigation with Muscodor albus. Biol. Control 32:401-407.

34. Mercier, J., and Wilson, C. L. 1995. Effect of wound moisture on the biocontrol by Candida oleophila of gray mold rot (Botrytis cinerea) of apple. Postharvest Biol. Technol. 6:9-15.

35. Mertely, J. C., MacKenzie, S. J., and Legard, D. E. 2002. Timing of fungicide applications for Botrytis cinerea based on development stage of strawberry flowers and fruit. Plant Dis. 86:1019-1024.

36. Mitchell, A. M., Strobel, G. A., Moore, E., Robison, R., and Sears, J. 2010. Volatile antimicrobials from Muscodor crispans, a novel endophytic fungus. Microbiology 156:270-277.

37. Nunes, C., Usall, J., Teixidó, N., Abadias, M., and Viñas, I. 2002. Improved control of postharvest decay of pears by the combination of Candida sake (CPA-1) and ammonium molybdate. Phytopathology 92:281-287.

38. Riga, E., Lacey, L. A., and Guerra, N. 2008. Muscodor albus, a potential biocontrol agent against plant-parasitic nematodes of economically important vegetable crops in Washington State, USA. Biol. Control 45:380-385 
39. Roilides, E., Farmaki, E., Evdoridou, J., Dotis, J., Hatziioannidis, E., Tsivitanidou, M., Bibashi, E., Filioti, I., Sofianou, D., Gil-Lamaignere, C., Mueller, F.-M., and Kremenopoulos, G. 2004. Neonatal candidiasis: Analysis of epidemiology, drug susceptibility, and molecular typing of causative isolates. Eur. J. Clin. Microbiol. Infect. Dis. 23:745-750.

40. Ruan, S.-Y., Chien, J.-Y., Hou, Y.-C., and Hsueh, P.-R. 2010. Catheterrelated fungemia caused by Candida intermedia. Int. J. Infect. Dis. 14:e147-e149.

41. Saravanakumar, D., Ciavorella, A., Spadaro, D., Garibaldi, A., and Gullino, M. L. 2008. Metschnikowia pulcherrima strain MACH1 outcompetes Botrytis cinerea, Alternaria alternata and Penicillium expansum in apples through iron depletion. Postharvest Biol. Technol. 49:121-128.

42. Schnabel, G., and Mercier, J. 2006. Use of a Muscodor albus pad delivery system for the management of brown rot of peach in shipping cartons. Postharvest Biol. Technol. 42:121-123.

43. Stinson, M., Ezra, D., Hess, W. M., Sears, J., and Strobel, G. 2003. An endophytic Gliocladium sp. of Eucryphia cordifolia producing selective volatile antimicrobial compounds. Plant Sci. 165:913-922.

44. Strobel, G. A., Dirkse, E., Sears, J., and Markworth, C. 2001. Volatile antimicrobials from Muscodor albus, a novel endophytic fungus. Microbiology 147:2943-2950.

45. Sutton, J. C., Li, D. W., Peng, G., Yu, H., Zhang, P. G., and ValdebenitoSanhueza, R. M. 1997. Gliocladium roseum: A versatile adversary of Botrytis cinerea in crops. Plant Dis. 81:316-328.

46. Tian, S. P., Yao, H. J, Deng, X., Xu, X. B., Qin, G. Z., and Chan, Z. L. 2007. Characterization and expression of $\beta$-1,3-glucanase genes in jujube fruit induced by the microbial biocontrol agent Cryptococcus laurentii. Phytopathology 97:260-268

47. Tronsmo, A., and Dennis, C. 1977. The use of Trichoderma species to control strawberry fruit rots. Neth. J. Plant Pathol. 83 (Suppl. 1):449-455.

48. Vaughn, S. F., Spencer, G. F., and Shasha, B. S. 1993. Volatile compounds from raspberry and strawberry fruit inhibit postharvest decay fungi. J. Food Sci. 58:793-796.

49. Vero, S., Mondino, P., Burgueño, J., Soubes, M., and Wisniewski, M. 2002. Characterization of biocontrol activity of two yeast strains from Uruguay against blue mold of apple. Postharvest Biol. Technol. 26:91-98.

50. Vespermann, A., Kai, M., and Piechulla, B. 2007. Rhizobacterial volatiles affect the growth of fungi and Arabidopsis thaliana. Appl. Environ. Microbiol. 17:5639-5641.

51. Wan, M. G., Li, G. Q., Zhang, J. B., Jiang, D. H., and Huang, H. C. 2008. Effect of volatile substances of Streptomyces platensis F-1 on control of plant fungal diseases. Biol. Control 46:552-559.

52. Williamson, B., Tudzynski, B., Tudzynski, P., and van Kan, J. A. L. 2007. Botrytis cinerea: The cause of gray mould disease. Mol. Plant Pathol. 8:561-580.

53. Wszelaki, A. L., and Mitcham, E. J. 2003. Effect of combinations of hot water dips, biological control and controlled atmospheres for control of gray mold on harvested strawberries. Postharvest Biol. Technol. 27:255264.

54. Yourman, L. F., and Jeffers, S. N. 1999. Resistance to benzimidazole and dicarboximide fungicides in greenhouse isolates of Botrytis cinerea. Plant Dis. 83:569-575.

55. Yu, G. F., Zheng, L., Mao, C. L., and Zhao, J. W. 2006. Epidemics and control of gray mould disease of strawberry. Shanghai Agric. Sci. Technol. Issue 1:122. (In Chinese)

56. Zhang, H. Y., Wang, L., Dong, Y., Jiang, S., Cao, J., and Meng, R. J. 2007. Postharvest biological control of gray mold decay of strawberry with Rhodotorula glutinis. Biol. Control 40:287-292.

57. Zhao, Y., Tu, K., Shao, X. F., Jing, W., and Su, Z. P. 2008. Effects of the yeast Pichia guilliermondii against Rhizopus nigricans on tomato fruit. Postharvest Biol. Technol. 49:113-120.

58. Zhou, M. G., Ye, Z. Y., Hang, J. S., and Liu, J. F. 1990. Research on formation and distribution of resistant strains to carbendazim in Botrytis cinerea on strawberry. J. Nanjing Agric. Univ. 13:57-60. (In Chinese with English abstract) 